\title{
Usefulness of Doppler echocardiographic assessment of diastolic filling in distinguishing "athlete's heart" from hypertrophic cardiomyopathy
}

Jannet F Lewis, Paolo Spirito, Antonio Pelliccia, Barry J Maron

\begin{abstract}
Objective-In some athletes with a substantial increase in left ventricular wall thickness, it may be difficult to distinguish with certainty physiological hypertrophy due to athletic training from hypertrophic cardiomyopathy. The purpose of the present investigation was to determine whether assessment of left ventricular filling could differentiate between these two conditions.
\end{abstract}

Design-Doppler echocardiography was used to obtain transmitral flow velocity waveforms from which indices of left ventricular diastolic filling were measured. Normal values were from 35 previously studied control subjects.

Setting-Athletes were selected mostly from the Institute of Sports Science (Rome, Italy), and patients with hypertrophic cardiomyopathy were studied at the National Institutes of Health (Bethesda, Maryland).

Participants-The athlete group comprised 16 young competitive athletes with an increase in left ventricular wall thickness (range 13-16 mm; mean 14). For comparison, 12 symptom free patients with non-obstructive hypertrophic cardiomyopathy were selected because their ages and degree of hypertrophy were similar to those of the athletes.

Results-In the athlete group, values for deceleration of flow velocity in early diastole, peak early and late diastolic flow velocities, and their ratio were not significantly different from those obtained in untrained normal subjects; furthermore, Doppler diastolic indices were normal in each of the 16 athletes. Conversely, in patients with hypertrophic cardiomyopathy, mean values for Doppler diastolic indices were significantly different from both normal subjects and athletics $(p=0.01$ to 0.003$)$, and one or more indices were abnormal in $10(83 \%)$ of the 12 patients.

Conclusions-Doppler echocardiographic indices of left ventricular filling may aid in distinguishing between pronounced physiological hypertrophy due to athletic training and pathological hypertrophy associated with hypertrophic cardiomyopathy.
(Br Heart J 1992;68:296-300)

Athletic training is often associated with a modest increase in left ventricular cavity size during diastole, ventral wall, wall thickness, and mass. ${ }^{1-10}$ Some athletes, however, may show considerable increase in left ventricular wall thickness. ${ }^{9}$ In such athletes, the presence of primary pathological hypertrophy due to hypertrophic cardiomyopathy may be difficult to exclude on a morphological basis alone. ${ }^{11} 12$

Pulsed Doppler echocardiography has been used extensively to assess left ventricular diastolic filling in normal subjects and in patients with various cardiac diseases ${ }^{13-20}$ including hypertrophic cardiomyopathy. Although previous studies have shown normal diastolic filling patterns in athletes with normal or mild left ventricular wall thickening, ${ }^{21-25}$ Doppler echocardiography has not been used to clarify the differential diagnosis between pronounced physiological hypertrophy due to athletic training ("athlete's heart") and hypertrophic cardiomyopathy. The present investigation applies Doppler indices of left ventricular diastolic filling to this clinical problem.

\section{Methods}

STUDY POPULATIONS

Our study population comprised 16 highly trained competitive athletes selected because of a considerable increase in left ventricular wall thickness ( $\geqslant 13 \mathrm{~mm}$ ). Fourteen were selected from a large group of elite Italian athletes who were all members of national teams and were evaluated at the Institute of Sports Science (Rome, Italy) between 1986 and 1988, as part of a mandatory annua medical evaluation. ${ }^{9}$ The other two athletes were selected from a group of competitive collegiate athletes at the University of Maryland, $1984-5 .^{26}$ These 16 athletes participated in rowing (11), canoeing (two), cycling (one), football (one), and running (one). Ages ranged from 18 to 26 (mean 22); all were men. Each athlete had normal blood pressure at the time of the evaluation, and none had a history of systemic hypertension or a family history of sudden cardiac death or hypertrophic cardiomyopathy.

Twelve patients with hypertrophic cardiomyopathy were also included. These patients were selected so that they would closely resemble the athletes in the study, by meeting the criteria: (a) comparatively mild 
left ventricular hypertrophy (for patients with hypertrophic cardiomyopathy) ${ }^{79}$ with maximum wall thickness $\leqslant 18 \mathrm{~mm} ;(b) \leqslant 30$ years of age; (c) symptom free; $(d)$ absence of systolic anterior motion of the mitral valve and haemodynamically significant mitral regurgitation; and $(e)$ no history of athletic training. Patients ranged in age from 11 to 30 (mean 23) years, and three were younger than $18(11,16$, and 17$) ; 10(83 \%)$ were men. Genetic transmission of hypertrophic cardiomyopathy was documented by clinical or echocardiographic findings in one or more relatives of nine of the 12 patients $^{27}$; the relatives of the other three patients did not undergo systematic echocardiographic studies. No patient was taking cardioactive drugs at the time of the study. Systemic blood pressure was within normal limits in each patient with hypertrophic cardiomyopathy.

Doppler echocardiographic findings in athletes and patients with hypertrophic cardiomyopathy were compared with values taken in our laboratory from 35 untrained normal subjects (mean age 22, range 19 to 29 years) without cardiovascular disease. ${ }^{15}$

\section{ECHOCARDIOGRAPHY}

Echocardiographic studies were carried out with an Advanced Technology Laboratory Mark 500 mechanical sector scanner or a Hewlett Packard 77020AC phased array sector scanner with a 2.5 or $3.5 \mathrm{mHz}$ transducer. Images were obtained in multiple cross sectional planes by standard transducer positions. ${ }^{28}$ Magnitude and distribution of left ventricular hypertrophy were assessed from the cross sectional echocardiogram by previously described methods. ${ }^{11}$

$M$ mode echocardiograms were derived from the cross sectional images under direct anatomical view and recorded on a strip chart at $50 \mathrm{~mm} / \mathrm{s}$ paper speed. Measurements of cardiac dimensions were taken from the $M$ mode echocardiogram according to the recommendations of the American Society of Echocardiography. ${ }^{29}$

\section{DOPPLER ECHOCARDIOGRAPHY}

Each subject was examined in the left lateral decubitus position by Doppler echocardiography with the transducer at or slightly to the left of the apical impulse. The transducer was orientated to get an apical four chamber

Table 1 Diastolic Doppler indices of left ventricular filling in competitive athletes with left ventricular hypertrophy, patients with non-obstructive hypertrophic cardiomyopathy (HCM), and untrained normal subjects (mean (SD)

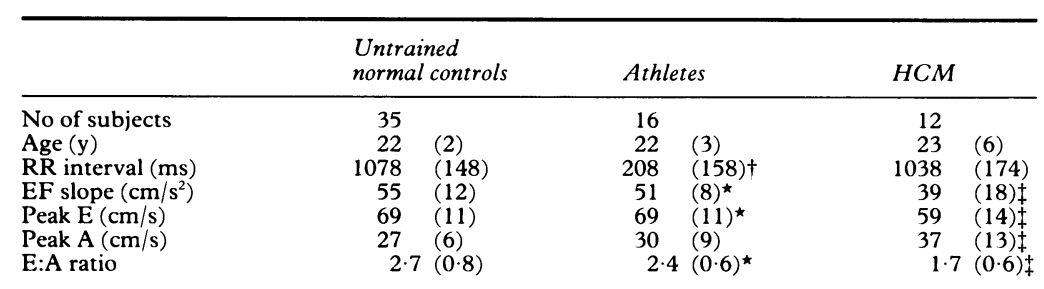

${ }^{\star} \mathrm{p}=0.04-0.005$, athletes $v$ HCM; $\nmid \mathrm{p}=0.01$, athletes $v$ HCM and controls; $\ddagger \mathrm{p}=0.01$ to $0 \cdot 0003$, HCM $v$ controls.

EF slope, rate of deceleration of flow velocity in early diastole; Peak E, peak flow velocity in early diastole; Peak A, peak flow velocity in late diastole; E:A ratio, ratio of early to late peak flow velocity. view of the heart that provided a good visualisation of the left ventricular cavity and maximal movement of the mitral valve leaflets. The Doppler cursor line was then positioned through a plane orientated perpendicularly to the mitral annulus and crossing the left ventricle from apex to centre of the anulus. Care was taken to minimise the angle between the presumed direction of diastolic transmitral blood flow and the ultrasound beam (cursor); this angle was estimated to be less than 20 degrees in each subject. The Doppler sample volume was positioned in the inflow area of the left ventricle between the mitral leaflets to maximise the peaks of diastolic flow velocity with the best graphic quality of the waveforms; the highest diastolic velocities were usually identified within the left ventricular cavity about $1 \mathrm{~cm}$ below the mitral anulus.

Doppler waveforms were recorded on a strip chart at $100 \mathrm{~mm} / \mathrm{s}$ paper speed. In each subject, three cardiac cycles with the most clearly defined flow velocity waveforms and the highest early diastolic peaks of flow velocity were selected for analysis. ${ }^{15}$ Left ventricular diastolic flow velocity waveforms from three cardiac cycles were measured and values averaged for the Doppler diastolic indices: $(a)$ early diastolic peak flow velocity, measured as the height of the early peak of flow velocity (E); (b) rate of decrease (deceleration) of flow velocity in early diastole (EF slope); (c) late diastolic peak flow velocity, measured as the height of the late (atrial) peak of flow velocity (A); and $(d)$ the ratio of the early to late peaks of flow velocity (E/A). These Doppler diastolic indices have already been shown to have satisfactory reproducibility. ${ }^{30}$

\section{STATISTICAL ANALYSIS}

Data are expressed as mean (SD). Differences in Doppler indices of diastolic filling among athletes, patients with hypertrophic cardiomyopathy, and normal controls were assessed by analysis of variance. Comparisons between two groups of subjects were tested with the unpaired Student's $t$ test. In individual subjects, any given Doppler diastolic index was considered abnormal when not within the $95 \%$ confidence intervals ( $95 \%$ CIs) of normal values. ${ }^{15}$ Upper and lower normal $95 \%$ CIs for the Doppler diastolic indices had been calculated from the one tail of the Student's $t$ test distribution as mean $+(1.684 \times \mathrm{SD})$, and mean $-(1.684 \times \mathrm{SD}) .{ }^{31}$ The transmitral waveform in each patient with hypertrophic cardiomyopathy (or athlete) was considered abnormal if the value for one or more of the Doppler indices of diastolic filling was outside this $95 \% \mathrm{CI}$.

\section{Results}

DOPPLER DIASTOLIC INDICES

Comparison of athletes and normal controls

In the athletes, mean values for deceleration of early diastolic flow velocity, early and late diastolic peak flow velocities, and the ratio of early to late peaks were similar and did not differ significantly from those of untrained, normal 


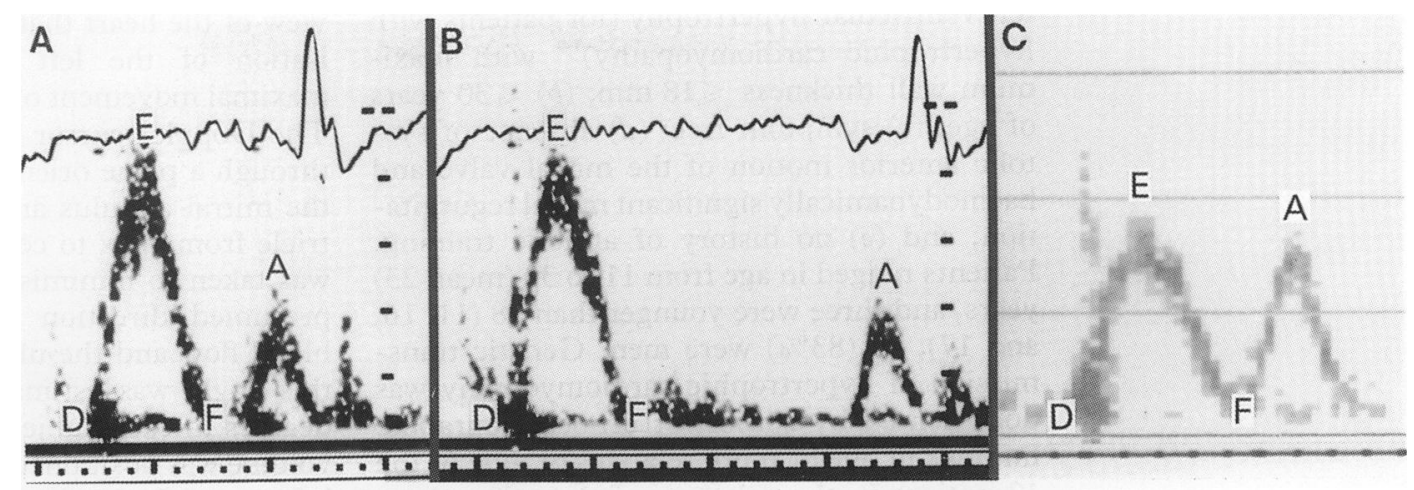

(A) Waveforms of transmitral flow velocity taken with Doppler echocardiography in a sedentary 20 year old man without cardiovascular disease; (B) an 18 year old highly trained football player; (C) a sedentary 19 year old symptom free patient with hypertrophic cardiomyopathy and relatively mild left ventricular hypertrophy. $(A)$ Normal diastolic waveform; deceleration of flow velocity in early diastole ( $E F$ slope) is rapid, and the height of early diastolic peak of flow velocity $(E)$ is more than twice that of late diastolic peak $A$. $(B)$ Pattern of the transmitral flow velocity waveform is similar to that of subject shown in panel $(A)$. (C) Abnormal pattern of transmitral flow velocity; deceleration of flow velocity in early diastole ( $E F$ slope) is decreased and the ratio of peak early $(E)$ to peak late flow velocity $(A)$ is reduced. Each vertical division represents a $20 \mathrm{~cm} / \mathrm{s}$ increment in flow velocity. Horizontal time line divisions are $40 \mathrm{~ms}$ apart.

subjects (table 1). Also, individual subject analysis showed that each index of diastolic filling of the left ventricle was within the $95 \%$ CI of the normal subjects in 15 of the 16 athletes (fig). The remaining athlete had only a mild increase in both the early and late peak flow velocities that were considered to occur as a normal consequence of increased stroke volume in this particular subject. Thus all 16 athletes had normal transmitral flow velocity waveforms. Heart rate in athletes was slower compared with normal controls (RR interval $1208(158) v 1078(148) \mathrm{ms}, \mathrm{p}<0 \cdot 1)$.

Comparison of patients with hypertrophic cardiomyopathy and normal controls In patients with hypertrophic cardiomyopathy, mean values for each of the Doppler diastolic indices measured were significantly different from those in the untrained normal subjectsthat is, patients with hypertrophic cardiomyopathy showed decreased early peak flow velocity, slowed deceleration of early diastolic flow velocity, and increased late peak flow velocity associated with atrial systole. Heart rates in the two groups were not significantly different (table 1). Furthermore, individual patient analysis showed that indices of left ventricular filling exceeded the $95 \% \mathrm{CI}$ of the untrained normal subjects in $10(83 \%)$ of the 12 patients with hypertrophic cardiomyopathy (fig). Of these 10 patients, three had one abnormal index, six had two abnormal indices, and one had three abnormal indices. The abnormalities of diastolic filling that occurred in patients with hypertrophic cardiomyopathy included decrease in early diastolic peak flow velocity $(<49 \mathrm{~cm} / \mathrm{s})$ in five patients, reduced deceleration of early diastolic flow velocity $(<35 \mathrm{~cm} / \mathrm{s})$ in five patients, increased late diastolic peak flow velocity $(<39 \mathrm{~cm} / \mathrm{s})$ in four patients, and reduced ratio of early to late peak flow velocities $(<1 \cdot 7)$ in four patients.

\section{Comparison of athletes and patients with} hypertrophic cardiomyopathy

In athletes mean values for deceleration of early diastolic flow velocity, early peak flow velocity, and the ratio of early to late peak velocities were significantly different from those from patients with hypertrophic cardiomyopathy ( $p<0.05)$, (table 1). Late diastolic peak flow velocity was similar in athletes and patients (table 1).

\section{CARDIAC DIMENSIONS}

Athletes

In the 16 athletes, thickness of the ventricular septum ranged from 13 to 16 (mean 14) mm and thickness of the posterior free wall ranged from 10 to 13 (mean 12) $\mathrm{mm}$. Substantial hypertrophy was confined to the ventricular septum in 13 athletes, and involved both septum and contiguous anterior free wall in three. The cavity dimension of the ventricle at end diastole ranged from 47 to 63 (mean 58 ) $\mathrm{mm}$ and was $>55 \mathrm{~mm}$ in 13 of the 16 athletes.

\section{Hypertrophic cardiomyopathy}

In the 12 patients with hypertrophic car-

Table 2 Cardiac dimensions in competitive athletes with left ventricular hypertrophy and patients with hypertrophic cardiomyopathy (HCM)

\begin{tabular}{|c|c|c|c|c|c|}
\hline \multirow[b]{3}{*}{$\begin{array}{l}\text { Age (y) } \\
\text { Ventricular septal thickness (mm) } \\
\text { Left ventricular posterior wall thickness }(\mathrm{mm}) \\
\text { Left ventricular end diastolic cavity dimension }(\mathrm{mm})\end{array}$} & \multicolumn{2}{|c|}{ Athletes $(n=16)$} & \multicolumn{2}{|c|}{$H C M(n=12)$} & \multirow[b]{2}{*}{ p Value } \\
\hline & Mean (SD) & Range & Mean (SD) & Range & \\
\hline & $\begin{array}{ll}22 & (3) \\
14 & (1) \\
12 & (1) \\
58 & (5)\end{array}$ & $\begin{array}{l}18-26 \\
13-16 \\
10-13 \\
47-63\end{array}$ & $\begin{array}{ll}23 & (6) \\
15 & (2) \\
11 & (1) \\
45 & (5)\end{array}$ & $\begin{array}{r}11-30 \\
13-18 \\
7-13 \\
38-56\end{array}$ & $\begin{array}{l}\text { NS } \\
\text { NS } \\
<0.05 \\
<0.001\end{array}$ \\
\hline
\end{tabular}


diomyopathy, thickness of the ventricular septum ranged from 13 to 18 (mean 15 ) $\mathrm{mm}$, and did not differ from that in the athletes (table 2). Thickness of the posterior free wall ranged from 7 to 13 (mean 11) $\mathrm{mm}$ and was slightly smaller than that in the athletes $(p<0.05)$ (table 2). Left ventricular hypertrophy was confined to the anterior ventricular septum in eight patients and involved both the septum and portions of the contiguous anterior free wall in the remaining four. The cavity dimension of the left ventricle at end diastole ranged from 38 to $56 \mathrm{~mm}$ and the mean value was significantly smaller than that in the athletes (45 (5) $v 58(5) \mathrm{mm}, \mathrm{p}<0.001)$.

\section{Discussion}

Long-term athletic training is known to produce physiological alterations in cardiac morphology that have been commonly referred to as the "athlete's heart". ${ }^{710}$ These changes usually consist of a modest increase in either cavity size of the left ventricle at diastole, ventricular wall thickness, or both. ${ }^{1-10} \mathrm{~A}$ minority of highly trained athletes, however, may show more substantial increases in thickness of the left ventricular wall (up to $16 \mathrm{~mm}$ ). ${ }^{9}$ On the other hand, hypertrophic cardiomyopathy is also characterised by increased thickness of the left ventricular wall. Whereas most patients with hypertrophic cardiomyopathy show a pronounced increase in left ventricular wall thickness of $20 \mathrm{~mm}$ or more, some patients with this disease may have mild increases in wall thickness of only $13-15 \mathrm{~mm} .^{122732}$ Hence, individual athletes with substantial left ventricular wall thickening create a diagnostic dilemma as it may be difficult to distinguish the "athlete's heart" from hypertrophic cardiomyopathy with comparatively mild left ventricular hypertrophy. The importance of this differential diagnosis becomes evident when one considers that the "athlete's heart" is a physiological condition not known to be associated with adverse pathological consequences, whereas hypertrophic cardiomyopathy seems to be the most common cause of sudden death in young competitive athletes. ${ }^{32-34}$

Several approaches have been suggested for the differential diagnosis between pronounced physiological hypertrophy and hypertrophic cardiomyopathy in athletes. Firstly, if hypertrophic cardiomyopathy can be documented in a relative of the athlete, this finding is strong evidence for genetically transmitted hypertrophic cardiomyopathy; however, about $45 \%$ of patients with hypertrophic cardiomyopathy have no evidence of familial transmission of the disease, and consequently a negative family study in the athlete does not absolutely exclude the possibility of hypertrophic cardiomyopathy. ${ }^{27}$ Secondly, as physiological left ventricular hypertrophy may show regression within weeks after the end of training, ${ }^{73}$ a period of planned deconditioning may induce a decrease in wall thickness in selected athletes that in turn would support the presence of physiological hypertrophy. ${ }^{7}$ The small changes in thickness of the wall of the left ventricle, however, that are induced by deconditioning may be difficult to identify reliably by echocardiography in the individual subject. Thirdly, the assessment of absolute size of the left ventricular cavity at end diastole may be useful in this differential diagnosis; for example, a small cavity ( $<45 \mathrm{~mm}$ ) would strongly suggest hypertrophic cardiomyopathy, whereas a cavity $>55 \mathrm{~mm}$ would favour the training effect of the "athlete's heart". ${ }^{70}$ In our study, the cavity dimension of the left ventricle at end diastole was in fact greater in athletes compared with patients with hypertrophic cardiomyopathy, although there was some overlap between the two groups. It should be emphasised, however, that the athletes in the study were mostly world class elite competitors who were engaged in particularly vigorous training programmes combining isotonic (endurance) and isometric (power) exercise. As a consequence, such subjects could be expected to have a larger left ventricular cavity than other competitive athletes. Finally, the possibility arises that absolute posterior wall thickness may be helpful in distinguishing "athlete's heart" from hypertrophic cardiomyopathy. Indeed, in our study, the mean value for thickness of the posterior free wall of the left ventricle was slightly greater in the athlete group than in patients with hypertrophic cardiomyopathy. The substantial overlap, however, between athletes and patients prohibits the use of this variable to distinguish physiological hypertrophy from hypertrophic cardiomyopathy in individual athletes. Hence, all the diagnostic approaches described have practical and methodological considerations that limit their usefulness in differentiating physiological from pathological wall thickening in individual athletes.

For these reasons, we considered the possibility that other non-invasive diagnostic tests might aid in the differentiation of "athlete's heart" from hypertrophic cardiomyopathy. Doppler echocardiographic assessment of left ventricular diastolic filling has been shown to be abnormal in most symptom free, as well as symptomatic, patients with hypertrophic cardiomyopathy, ${ }^{15}$ and also in patients with various other cardiac diseases. ${ }^{1317} 18$ Therefore, we chose Doppler echocardiography to compare left ventricular filling in competitive athletes who have considerable physiological hypertrophy with symptom free patients who have non-obstructive hypertrophic cardiomyopathy and mild pathological hypertrophy. These two groups were intentionally selected to be similar for wall thickness and age. ${ }^{36}$ Despite these similarities, each of the 16 athletes had a normal pattern of left ventricular filling, whereas more than $80 \%$ of the patients with hypertrophic cardiomyopathy had an abnormal filling pattern. Therefore, an abnormal Doppler diastolic waveform in an athlete with considerable left ventricular hypertrophy would strongly suggest the presence of hypertrophic cardiomyopathy, whereas a normal Doppler filling pattern does not exclude the diagnosis of hypertrophic cardiomyopathy. ${ }^{1520}$ The athletes, as a group, had slightly slower 
heart rates than either normal subjects or patients with hypertrophic cardiomyopathy. There is, however, no evidence suggesting that such a modest difference in heart rate could have accounted for the differences in early diastolic peak flow velocity between these two groups. Whereas alterations in the transmitral flow velocity waveform have been reported to be associated with increased heart rate, these changes were elicited under non-physiological conditions (that is, with intracardiac or transoesophageal pacing $)^{37} 38$ and may not be applicable to the small differences in resting heart rate found under physiological conditions in our subjects. Moreover, these reported rate related alterations in the transmitral waveform consisted mostly of increases in the late diastolic flow velocity, by contrast with the differences in early flow velocity that we found between athletes and patients with hypertrophic cardiomyopathy.

This study was supported in part by grant HL 01984 from the National Institutes of Health, Bethesda, Maryland.

1 Adams TD, Yanowitz FG, Fisher AG, Ridges JD, Lovell K, Pryor TA. Noninvasive evaluation of exercise training in college-age men. Circulation 1981;64:958-65.

2 Sugishita Y, Koseki S, Matsuda M, Yamaguchi T, Ito I Myocardial mechanics of athletic heart in comparison with diseased hearts. Am Heart J 1983;105:273-80.

3 Panidis IS, Kotler MN, Ren JF, Mintz GS, Ross J, Kalman $P$. Development and regression of left ventricular hypertrophy. J Am Coll Cardiol 1984;3:1309-20.

4 Hutson TP, Puffer JC, MacMillan W. The athlete heart syndrome. N Engl J Med 1985;313:24-32.

5 Lusiani L, Ronisisvalle G, Bonanome A, et al. Echocardiographic evaluation of the dimensions and systolic properties of the left ventricle in freshman athletes during physical training. Eur Heart J 1986;7:196-203.

6 Colan SD, Sanders SP, Barow KM. Physiologic hypertrophy: effects on left ventricular systolic mechanics in trophy: effects on left ventricular systolic

7 Maron BJ. Structural features of the athlete heart as defined by echocardiography. J Am Coll Cardiol 1986;7:190-203. 8 Douglas PS, O'Toole ML, Hiller WDB, Reichek N. Lef ventricular structure and function by echocardiography in ultraendurance athletes. Am J Cardiol 1986;58:805-9.

9 Pelliccia A, Maron BJ, Spataro A, Proschan MA, Spirito P The upper limit of physiologic cardiac hypertrophy in highly trained elite athletes. $N$ Engl J Med 1991;324 295-301.

10 Rost R. The athlete's heart. Eur Heart J 1982;3(suppl A): 193-8.

11 Maron BJ, Gottdiener JS, Epstein SE. Patterns and significance of distribution of left ventricular hypertrophy in hypertrophic cardiomyopathy: a wide angle, two-dimenhypertrophic cardiomyopathy: a wide angle, two-dimenSional echocardiographic

12 Spirito P, Maron BJ, Bonow RO, Epstein SE. Severe functional limitation in patients with hypertrophic cardiomyopathy and only mild

13 Rokey R, Kuo LC, Zogbi WA, Limacher MC, Quinones MA. Determination of parameters of left ventricular diastolic filling with pulsed Doppler echocardiography: comparison with cineangiography. Circulation 1985;71: 543-50.

14 Gardin JM, Rohan MK, Davidson DM, et al. Doppler transmitral flow velocity parameters: relationship between age, body surface area, blood pressure and gender in normal subjects. American Journal of Noninvasive Cardiology 1987;1:3-10.
15 Maron BJ, Spirito P, Green KJ, Wesley YE, Bonow RO, Arce J. Noninvasive assessment of left ventricular diastolic function by pulsed Doppler echocardiography in patients with hypertrophic cardiomyopathy. $\mathrm{J}$ Am Coll Cardiol 1987;10:743-7.

16 Spirito P, Maron BJ. Doppler echocardiography for assessing left ventricular diastolic function. Ann Intern Med 1988;109:122-6.

17 Philips RA, Coplan NL, Krakoff LR, et al. Doppler echocardiographic analysis of left ventricular filling in treated diographic analysis of left ventricular filling in treated

hypertensive patients. $J$ Am Coll Cardiol 1987;9:317-22.
18 Appleton CP, Hatle LK, Popp RL. Relation of transmitral flow-velocity patterns to left ventricular diastolic function: new insights from a combined hemodynamic and Doppler echocardiographic study. J Am Coll Cardiol 1988;12: $426-40$.

19 Bryg RJ, Pearson AC, Williams GA, Labovitz AJ. Left ventricular systolic and diastolic flow abnormalities determined by Doppler echocardiography in obstructive hypertrophic cardiomyopathy. Am J Cardiol 1987;59. 925-31.

20 Gardin JM, Dabestani A, Glasgow GA, Butman CS, Henry WL. Echocardiographic and Doppler flow observations in obstructed and nonobstructed hypertrophic cardiomyopathy. Am J Cardiol 1985;56:614-21.

21 Colan SD, $A m$ Sanders SP, MacPherson D, Borow KM. Left ventricular diastolic function in elite athletes with ventricular diastolic function in elite athletes with
physiologic cardiac hypertrophy. $J$ Am Coll Cardiol 1985; physiologic

22 Granger CB, Karuimeddini MK, Smith VE, Shapiro HR, Katz AM, Riba AL. Rapid ventricular filling in left ventricular hypertrophy. I. Physiologic hypertrophy. J Am Coll Cardiol 1985;5:862-8.

23 Pearson AC, Schiff M, Mrosek D, Labovitz AJ, Williams GA. Left ventricular diastolic function in weight lifters. Am J Cardiol 1986;58:1254-9.

24 Fagard R, Van den Broeke C, Bielen E, Vanhees L, Amery A. Assessment of stiffness of the hypertrophied left ventricle of bicyclists using left ventricular inflow Doppler of bicyclists using left ventricular inflow

25 Finkelhor RS, Hanak LJ, Bahler RC. Left ventricular filling in endurance-trained subjects. J Am Coll Cardiol 1986;8: 289-93.

26 Maron BJ, Bodison SA, Wesley YE, Tucker E, Green KJ Results of screening a large group of intercollegiate competitive athletes for cardiovascular disease. $\mathrm{J} \mathrm{Am} \mathrm{Coll}$ Cardiol 1987;10:1214-21.

27 Maron BJ, Nichols PF, Pickle LW, Wesley YE, Mulvihill JJ. Patterns of inheritance in hypertrophic cardiomyopathy: assessment by $\mathbf{M}$-mode and two-dimensional echocardiography. Am J Cardiol 1984;53:1087-94.

28 Tajik AJ, Seward JB, Hagler DJ, Mair DD, Lie JT. Twodimensional real-time ultrasound imaging of the heart and great vessels: technique, image orientation, structure identification and validation. Mayo Clin Proc 1978;53: 271-303.

29 Sahn DJ, DeMaria A, Kisslo J, Weyman A Recommendations regarding quantitation in M-mode echocardiotions regarding quantitation in M-mode echocardiography: results of a survey of echocard

30 Spirito P, Maron BJ, Verter J, Merrill JS. Reproducibility of Doppler echocardiographic measurements of left ven tricular diastolic function. Eur Heart $J$ 1988;9:879-86.

31 Snedecor GW, Cochran WG. Statistical methods. 8th ed Ames, Iowa: Iowa State University Press, 1989:55-7.

32 Maron BJ, Bonow RO, Cannon RO, Leon MB, Epstein SE Hypertrophic cardiomyopathy: interrelations of clinical manifestation, pathophysiology and therapy. $N$ Engl Med 1987;316:780-9, 844-52.

33 Maron BJ, Roberts WC, McAllister HA, Rosing DR, Epstein SE. Sudden death in young athletes. Circulation 1980;62:218-29.

34 Maron BJ, Epstein SE, Roberts WC. Causes of sudden death in competitive athletes. J Am Coll Cardiol 1986;7:204-14.

35 Ehsani AA, Hagberg JM, Hickson RC. Rapid changes in lef ventricular dimensions and mass in response to physical ventricular dimensions and mass in response to physical
conditioning and deconditioning. Am J Cardiol 1978;42: cond 6 -6.

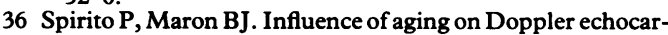
diographic indices of left ventricular diastolic function. $\mathrm{Br}$ Heart J 1988;59:672-9.

37 Harrison MR, Clifton D, Pennell AT, DeMaria AN. Effect of heart rate on left ventricular diastolic transmitral flow velocity patterns assessed by Doppler echocardiography in normal subjects. Am J Cardiol 1991;67:622-7.

38 Herzog CA, Elsperger J, Manoles M, Murakami M, Asinger R. Effect of atrial pacing on left ventricular diastolic filling measured by pulsed Doppler echocardiography [abstract] J Am Coll Cardiol 1987;9:197A. 